\title{
A STUDY ON KEY FACTORS BEHIND THE INTENSIVE DEVELOPMENT OF CHINA'S RURAL HOUSING
}

\author{
ZOU, S. X. \\ School of Marxism, China University of Geosciences \\ Xueyuan Road, Haidian District, Beijing 100083, China \\ e-mail:zoushx@cugb.edu.cn
}

(Received 11 $1^{\text {th }}$ Aug 2016; Accepted $15^{\text {th }}$ Nov 2016)

\begin{abstract}
This paper aims to sort out the development history of China's urbanization, analyze the impact of urbanization on the intensive development of rural housing, and summarize the status quo and existing problems in China's rural housing management. On the basis of the foregoing, an intensive development model for rural housing is created, which is oriented towards urbanization, with a view to promoting the development of the new countryside construction. In this research, sample surveys on resident families under the program of intensive development of rural housing in Zhejiang Province are taken as the analysis object. It is concluded from the research that: The most prized dimension is the "governmental factor". The most prized indicator factors include: government-led business operations, urban employment opportunities, scientific planning, residential land use right transfer and residential environment. Based on the analysis of the empirical results, the following conclusions are put forth in this paper. In so doing, we hope to provide clear guidance and direction for the intensive development of China's rural residential houses in the context of urbanization. These efforts will help improve rural housing management, promote the intensive development of rural housing, and contribute to the urbanization process with Chinese characteristics.
\end{abstract}

Keywords: housing management, urbanization, intensive development, Jiaxing, model

\section{Introduction}

The formation of metropolises was primarily affected by the human beings' mode of production and economic development, following an evolution from the formation of early tribes through food collection and nomadism to villages mainly engaged in agricultural activities, and finally to the industrial revolution. Population from towns and villages has been flocking to cities, so that metropolises were formed. As a part in the historical category, urbanization is a concept in the process of development. It can be elaborated from different perspectives, including demography, geography, sociology, and economics. Since ancient times, people have been tending to live together for safety, water and food. These places are usually located along important lines of communications, such as ports, railways and other production centers. The invention and popularization of vehicles have enabled people to select relatively distant residential environments so that their living and residential methods underwent changes in the course of movement. In summary, the so-called "urbanization" means the process of the rural population's permanent migration to cities, and the second and tertiary industry's constant clustering in cities, which results in continuous increase in the number of cities and expansion of the urban sizes, as well as the growing dissemination of urban production modes, living methods and core values. As a historical environment, urbanization has become an irresistible trend in the human being's socioeconomic development and civilization progress. With cities being the destinations for 
urbanization, the quantity and size of cities will determine the urbanization level. The promotion of intensive development of residential houses in China's rural areas will be conducive to the vigorous development of the urbanization process in the new century.

\section{Review of Literature}

\section{New Urbanism}

According to Ho and Gao (2013), New Urbanism is a kind of activity under the modern urban planning, intended to revitalize the redevelopment of the principles and applications of traditional urban elements arising from the late $19^{\text {th }}$ century and early $20^{\text {th }}$ century in areas to be built. It calls for the changes to an urban form dominated by the traditional residence-business separation, in order to avoid monotonous and isolated urban living space resulting from metropolitan residential area. The New Urbanism has become a most common used method for the suburban development in the United States. In order to realize the dream of calm, peaceful and undisturbed suburban life, the following points must be covered in the physical space planning: (I) Simple residential areas, with the intensity and purpose of use being controlled on the basis of the explicit use zoning; ( II) Small-sized recreational vehicles are used as the main means of transport, road and fast road networks are build based on the road hierarchy; (III) People's own residential houses must keep distance from their working place; (IV) Social classes are shown in distinguished areas on the map, indicating city centers are no longer a single core, but has been converted into a convenient transportation hub, a business district and places of residence for the middle and lower classes, while high-earning classes live the suburbs and can use their own car for commuting (Means, 2011); and (V) For urban public facilities, a higher percentage of funds must be spent on roads and parking spaces than previous urban planning. Therefore, roads are primarily used for vehicles (Najafi, 2010). According to Nguyen (2012), in terms of the spirit of New Urbanism, the configuration of buildings and open spaces are used to emphasize spatial scale and density, spatial hierarchy and connectivity, and uphold the planning concept whereby New Urbanism is designed for the whole community based on the similar principles. It is expected to provide a mixed and varied use to meet the needs of local residents. Within the neighborhood center, schools, markets, public facilities, etc. must be made available, while people from the community can reach neighborhood center on foot within five minutes. Its planned cities are classified on the basis of the concept of the neighborhood units. The New Urbanism neighborhood units are governed by the following principles (Opoku and Abdul-Muhmin, 2010):

- It must have a clear center and marginality. Neighborhood unit centers are usually located at important crossroads, and are where public facilities (post offices, cultural centers, etc ...) are located. With squares and green fields used as public spaces, work and shopping center sites can be connected with the centers, and commercial and community activities with neighborhood features can be integrated to enhance the centers' functions. (Habib et al., 2011).

- With 1/4 mile taken as the best neighborhood size and five minutes walking distance as the standard, residents are expected to complete the required activities of daily living within this distance. Stations can be connected with the surrounding areas to increase willingness for commuting. 
- Mixed and varied uses will be required. Commercial, residential, work, entertainment and other different functions must be used in combination, and people are encouraged to walk to expand the scope of activities of different ages, and to provide different housing forms, and people with different incomes can integrated in a single neighborhood (Lai, 2011).

- Buildings and transportation must be covered in a good network. In the street blocks, pedestrians' walking distances will be shortened, and various types of neighborhood streets will be provided for the use of people and vehicles, in order to avoid the entry of transit vehicles into the local streets. Cal-de-sec and ring roads will be utilized to reduce the connection between people and vehicles (Means, 2011).

- Public spaces and buildings must be given top priority. The public nature of public facilities will be utilized to strengthen the relationship between the housing districts, and with the support of and with gradational streets, street blocks and squares, the roles of neighborhood centers will be enhanced so that they become the neighborhood landmark (Zhang et al., 2011).

\section{Review of China's urbanization process}

According to National Bureau of Statistics (2015), China's cities and towns are classified into two types, i.e., large cities and small towns. The word "cities" refers to those cities duly established with the approval of competent governments of the People's Republic of China. Based on the size of non-agricultural population in urban areas, cities are divided into: megacities (with a population of 2 million and above), supercities (with a population of 1-2 million), large cities (with a population of $500,000-1$ million), medium-sized cities (with a population of $200,000-500,000$ ) and small cities (with a population of less than 200,000). Originally referring to the places where governments of duly established towns are located, the scope of small towns has since expanded and is determined primarily on the basis of populations and functions. The two major destinations of China's urbanization include large/small cities and towns widely distributed in the rural areas. The urbanization process arising from the intensive construction of rural housing as mentioned herein covers both large/small cities and small towns, with more emphasis placed on small towns in rural areas. The first stage: the stage of steady development (1949-1957). According to Zhang et al. (2011), during the period when New China was just founded, when no clear urbanization policy was formulated, and there was no policy restriction on rural population's entry into cities for settlement and employment, rural population can freely move into cities, which promoted the rapid development of urbanization for this period. The second stage: the stage of fluctuated development (1958-1978). During this period, the urbanization development was affected by the national macro-policy failures and experienced sharp fluctuations. As the iron and steel production campaign ignited a wave of China's industrialization, and rapid development of the industrial sector required numerous labor forces, a large number of rural people moved to work in the industrial sector, which promoted the hyper-growth of urbanization and urban population surge. Starting from 1959, the national economy experienced a severe recession, unable to support the rapid growth of urban population, resulting in a significant decline in urban population, and ushering in a fluctuation period dominated by stagnation and decline. According to Zhang et al. (2011), with the revitalization and consolidation of the national economy in 
1964, the population control was modestly relaxed, and by 1965 , the urbanization rose to a level comparable with that in 1957. Due to impact of the Cultural Revolution, the national economy stood at the verge of collapse. In the winter of 1966, nearly ten million urban residents in rural areas were repatriated to the rural areas, and in 1968, more than 20 million urban young students were sent to the mountainous areas and the countryside, causing the urban population growth to decline and hover at around $17 \%$. As a result, the urbanization level during this period maintained a stagnant and declining trend. The third stage: stage of rapid development (after 1978) (National Bureau of Statistics, 2015). According to Zhang et al. (2011), after the end of the "Cultural Revolution", the political order was brought out of chaos to normal and policies were adjusted, so that a large number of educated young people sent to the mountainous areas and the countryside as well as cadres transferred to a lower level or to do manual labor in the countryside or in a factory returned to their cities, and the university entrance exam was restored. All these changes resulted in rapid growth in the urban population, relatively rapid restoration of the urbanization level, and rise in the urban population. This symbolizes a rebound from the decline of the urbanization level. According to Babbie (2013), with the rapid development of township enterprises and the rapid increase in small towns since the mid-eighties, the focus of reforms has been gradually shifting to cities. China's industrialization entered a stage of rapid development, resulting in a rapid growth in urban population. Since the beginning of the twenty-first century, China has been making all-out efforts to speed up the pace of urbanization, resulting in a rapid rise in the urbanization rate. During this period, China's socialist market economic system underwent gradual improvement since its establishment, and the pace of urbanization and industrialization was further accelerated. Through the pilot implementation and gradual popularization of the urban and rural area integration reforms starting from 2008, the urbanization level witnessed rapid improvement.

As seen from the perspective of China's urbanization development history, China has emerged from a backward agricultural country with a low urbanization level, and embarked on an evolution from a typical agricultural country to an industrialized and modernized country, after 60 years of development with the support of the country's transformation from a planned economic system to a socialist market economic system featured with reforms and opening-up. Its urbanization level has remarkably improved, and a development road to urbanization with Chinese characteristics has taken shape. All the foregoing developments will provide historical and realistic foundations for the promotion of urbanization construction and development by mobilizing farmers to collectively live in cities through the intensive construction of rural housing.

\section{Analysis on the status quo and existing problems relating to China's rural housing Management}

According to Peng (2009), due to the expanding population in China, the social system transformation and the development of the modernization drive, the contradiction between people and places has become more apparent. It has become an even more arduous task to comply with the red line for arable land. The legislation relating to residential land management is growingly lagging behind. With the vigorous promotion of the construction of the new socialist countryside, the organization of rural 
housing is playing a growingly important role in the construction of the new countryside. However, the status quo of rural housing management allows for no optimism. The problems existing in rural housing management lie in the following three aspects:

- Rural houses are constructed in a distracted structure, adversely affecting the urbanization of the rural areas

Given that no sufficient guidance relating to village and town construction is available for the construction of farmers' houses, farmers' houses are constructed in a casual manner, resulting in scattered layout and differentiated structures. A large number of "hollow villages" have emerged, causing severe waste to rural land, poor rural images and lack of infrastructure. The scattered distribution of residential land in the rural areas and the problem of separate arrangements for farmers' housing construction will adversely affect farmers' concentration in cities/towns and central villages, and the popularization of intensive land use and urbanization in rural areas (Najafi, 2010).

- Rural housing is managed in an irregular manner under imperfect market mechanism

According to Peng (2009), no independent laws and regulations are available to govern China's rural housing management. Relevant rules can be found in miscellaneous laws concerning land management. In addition, the local conditions differ greatly across China, and law enforcement is not carried out in a consistent manner, resulting in lack of a unified standard management. Certain serious problems exist, such as farmers' excessive occupation of residential land and invisible transfer of residential land. A market-oriented money-raising mechanism is lacking, resulting in shortage of funds for rural residential land consolidation. The consolidation of rural residential land and concentration of residential areas require a huge amount of funds, which is not affordable by reliance on governmental fiscal subsidies and farmers' own financing. According to Ho and Gao (2013), Infrastructure construction such as old house demolishing, land consolidation, roads, water and power supply and telecommunications require a considerable amount of preliminary funding. Insufficient fiscal subsidies, heavy fund pressure in infrastructure construction, unavailability of supporting funds, lack of incentive measures for farmers' relocation to new village areas and construction of houses, and especially the low level of financial subsidies and allowances for residential land consolidation, have affected farmers' enthusiasm for demolishing the old houses and building new houses, resulting in slow progress in farmers' intensive construction of houses and slow-down in the progress of new village construction (Nieboer, 2012).

- No effective guidance for the intensive construction of rural housing, affecting the development of the modernization drive in the rural areas

According to Peng (2009), no sufficient attention has been given to the consolidation of rural housing. Currently, leading cadres in the rural areas, especially cadres at the county and township levels attach greater importance to economic indicators and place one-sided emphasis on economic growth and increase in farmers' incomes, while no sufficient attention is given to rural social management. In the area of land management, special attention is given to protection of arable land and agricultural land transfer, while the development and consolidation of residential land have not been put on the agenda. No efforts have been made to effectively strengthen the development and consolidation of rural housing, taking into account the requirements for tidy village image in the new village construction, the purpose of ensuring the red line for arable 
land, and the necessity for improving farmers' residential and living quality. According to Lai (2011), the role of guiding and constraining the intensive construction of residential housing based on the village and town construction planning has not been sufficiently played. Village/town construction planning should play a leading role in the construction of rural houses and will have a direct controlling impact on the construction of farmers' houses.

For a long period of time, no importance is attached to the planning's guiding roles in China's rural construction. The lagging planning of rural construction, and lack of necessary land use planning, village/town construction planning and planning of arable land consolidation have adversely affected the new village construction. According to Peng (2009), Over the recent years, as the state values and emphasizes the rural planning and construction, rural planning and construction start to make progress, but a number of problems still exist in the scientific, applicable and operable nature of village/town construction planning. Governments at various levels shall assume the major responsibilities for formulating overall land use plans, village/town construction plans, arable land consolidation plans and other plans, and supervising the implementation thereof. The supervision and service functions of governments at various levels shall be continuously strengthened. According to Means (2011), Scientific and feasible village/town construction planning can effectively guide the intensive construction and consolidation of rural housing, which will have a positive impact on the local economic development, and facilitate the construction of public service facilities and the improvement of farmers' living quality. In consideration of this, the intensive construction of rural housing will become an important supporting for promoting the development of the new village modernization drive.

\section{Research Design and Methods}

\section{Delphi method}

This method aims to build AHP dimension criteria based on the Delphi Method. The Delphi Method is also called the Method of Specialist Investigation, a decision-making method whereby the problems to be solved are sent to individual experts separately via a proper communication method for comments, opinions are collected from all experts and summarized, comprehensive opinions will be worked and, together with predicted problems, submitted to the experts for further opinions, and all experts will revise their original opinions based on the comprehensive opinions, and the further opinions will be summarized, and unanimous prediction results will be reached gradually upon the repetition of the foregoing processes.

The Delphi Method adopts a method of making anonymous comments based on systematic programs, which means experts shall not discuss with each other and shall have no mutual contacts, and may only have relationship with the surveyors. Through several rounds of survey of experts' opinions on the presented problems, and upon repeated enquiry, summary and revision, a basically unanimous expert opinion will eventually be summarized as the prediction result. This method is widely representative and relatively reliable. 


\section{Establishment of evaluation indicators}

This questionnaire will be sent to experts in various areas via email. The first action will be to collect and summarize feedbacks from the experts, and sort out the items to be considered with respect to the intensive development of China's rural housing in the context of urbanization. Subsequently those considerations in similar nature will be put in the same category, and sent to the experts for their comments. Repeated communications with the experts will be conducted until the final opinions are received. Finally, they will be classified by large items, and an expert meeting will be called and experts to gather together to work out the key factors determining the intensive development of China's rural housing in the context of urbanization, i.e., government factor, economic factor and environmental factor. Then an AHP questionnaire will be created by using these key factors as AHP dimensions and various corresponding classifications as the criteria. The key factors revised in the Delphi Method in this research are shown as follows

- Governmental factor: scientific planning, transfer of residential land use right, business activities led by the government;

- Economic factor: urban real estate prices, capitalization, urban employment opportunities, original values of residential land

- Environmental factor: the intensive level of public services systems, residential environment, and reforms of the household registration system

\section{Research object}

In this research, sample surveys on resident families under the program of intensive development of rural housing in Zhejiang Province are taken as the analysis object. In the research, 500 copies of questionnaires were distributed, and 366 valid questionnaires were collected, with a response rate of $73 \%$. At present, in order to reasonably address the contradiction between construction and livelihood, the Jiaxing City puts the construction of rural apartments on the top agenda of its village/town construction. Over the recent two years, a total of 6,500 suites of rural apartments have been built, attracting more than 19,500 farmers and saving more than 2,000 mu arable land. This year, the construction of additional 1,100 suites of apartments will be completed. In consideration of this, the residential families of the rural apartments in Jiaxing are used as the research samples.

\section{Data Analysis and Results}

Upon evaluating all the hierarchical weightings, allocations will be made on the basis of the relative importance of the hierarchical evaluation indicators, indicating the importance of the relevant hierarchy's indicators in the whole evaluation system, and giving rise to an overall weighting for the evaluation of the intensive development of China's rural housing in the context of urbanization, as summarized in Table 1.

The following conclusion can be drawn on the basis of the foregoing Table 1 resulting from analysis and summarization of the questionnaires:

Among the second-level evaluation dimensions, the most valued dimension is the "governmental factor", which has a weighting of 0.412 , accounting for $41.2 \%$ of the total weighting. Other valued dimensions are respectively "economic factor" (with a 
weighting of 0.357) and "environmental factor" (with a weighting of 0.231). It can be learned from the survey result that the most valued dimension for the intensive development of China's rural housing in the context of urbanization is the governmental factor.

The following conclusion can be drawn on the basis of the foregoing Table 1 resulting from analysis and summarization of the questionnaires:

Among the second-level evaluation dimensions, the most valued dimension is the "governmental factor", which has a weighting of 0.412 , accounting for $41.2 \%$ of the total weighting. Other valued dimensions are respectively "economic factor" (with a weighting of 0.357 ) and "environmental factor" (with a weighting of 0.231 ). It can be learned from the survey result that the most valued dimension for the intensive development of China's rural housing in the context of urbanization is the governmental factor.

\section{Conclusion and Suggestions}

Based on the analysis of the empirical results, the following conclusions are put forth in this paper. In so doing, we hope to provide clear guidance and direction for the intensive development of China's rural residential houses in the context of urbanization.

Table 1. Summary of the Overall Weightings for the Intensive Development of China's Rural Housing in the Context of Urbanization

\begin{tabular}{|c|c|c|c|c|c|}
\hline Dimension & $\begin{array}{c}\text { Level } 2 \\
\text { Weighting }\end{array}$ & $\begin{array}{c}\text { Level } 2 \\
\text { Sequencing }\end{array}$ & Indicator & $\begin{array}{c}\text { Overall } \\
\text { Weighting }\end{array}$ & Overall Sequencing \\
\hline \multirow{3}{*}{$\begin{array}{l}\text { Governmental } \\
\text { factor }\end{array}$} & \multirow{3}{*}{0.412} & \multirow{3}{*}{ 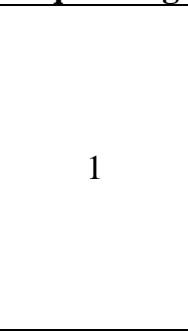 } & $\begin{array}{l}\text { Scientific } \\
\text { planning }\end{array}$ & 0.123 & 3 \\
\hline & & & $\begin{array}{l}\text { Residential land } \\
\text { use right } \\
\text { transfer }\end{array}$ & 0.112 & 4 \\
\hline & & & $\begin{array}{c}\text { Government-led } \\
\text { business } \\
\text { activities } \\
\end{array}$ & 0.164 & 1 \\
\hline \multirow{4}{*}{$\begin{array}{l}\text { Economic } \\
\text { factor }\end{array}$} & \multirow{4}{*}{0.357} & \multirow{4}{*}{2} & $\begin{array}{c}\text { Urban housing } \\
\text { prices }\end{array}$ & 0.074 & 7 \\
\hline & & & Capitalization & 0.070 & 8 \\
\hline & & & $\begin{array}{c}\text { Urban } \\
\text { employment } \\
\text { opportunities }\end{array}$ & 0.146 & 2 \\
\hline & & & $\begin{array}{c}\text { Value of } \\
\text { original } \\
\text { residential land }\end{array}$ & 0.066 & 9 \\
\hline \multirow{3}{*}{$\begin{array}{l}\text { Environmental } \\
\text { factor }\end{array}$} & \multirow{3}{*}{0.231} & \multirow{3}{*}{3} & $\begin{array}{c}\text { Intensive } \\
\text { degree of public } \\
\text { service systems }\end{array}$ & 0.085 & 6 \\
\hline & & & $\begin{array}{l}\text { Residential } \\
\text { environment }\end{array}$ & 0.097 & 5 \\
\hline & & & $\begin{array}{l}\text { Reforms of the } \\
\text { household } \\
\text { registration } \\
\text { system }\end{array}$ & 0.063 & 10 \\
\hline
\end{tabular}


On the basis of analyzing the factors constituting the intensive development model for rural housing, as well as the different roles of the actual and constituent factors in the intensive housing development in different regions of China, the author classifies the intensive development model for rural housing into two types: the model of using rural residential land in exchange for urban housing and the model of waiving rural residential land + economic compensation. Each model includes basic factor, key factor and auxiliary factor. A detailed analysis of two of the factors are provided below.

\section{The model of using rural residential land for urban housing}

The model of using rural residential land in exchange for urban housing is a model whereby farmers use their originally owned residential land in exchange for urban housing pursuant to agreed-upon terms and conditions. Specifically, it can be divided into two forms, i.e., using rural residential land in exchange for urban housing and using rural residential land in exchange for urban housing + industrial premises. Farmers using rural residential land in exchange for urban housing may operate or transfer the contracted land, and normally will not waive the use right to the contracted land. Farmers under the model of using rural residential land in exchange for urban housing + industrial premises may find jobs or start their own businesses in cities/towns, and normally will not operate the contracted land by themselves, but may transfer the right to the operation of the contracted land for profits. This model is suitable for a large number of people and covers a large scope of areas. Farmers may also select using rural residential land in exchange for urban housing or for industrial premises from these two methods. Normally, in economically developed rural areas, farmers tend to select to using rural residential land in exchange for urban housing and using residential land in exchange for urban housing + industrial premises. In rural areas with their economy not sufficiently developed, especially in regions where the second and tertiary industries are not sufficiently developed, farmers tend to choose the method of using their residential land in exchange for houses in central villages, operate or transfer the operating right to contracted land for profits.

\section{The model of waiving residential land + economic compensation}

The model of waiving residential land + economic compensation is a model whereby farmers with their households registered under their respective collective economic organizations waive their originally owned residential land, and waive the entitlement to receive a piece of residential land without charge from their respective collective economic organizations, which is equivalent to waiving their entitlements to receiving residential land in China's rural areas (because under Chinese laws and regulations, farmers can only receive a piece of residential land without charge from the rural collective economic organization under which their households are registered), and will be paid an economic compensation as replacement. The amount of the economic compensation will be determined by the village collective economic organization and the agricultural development company based on the evaluation of originally owned residential land. The most important feature of this model is the waiver of the originally owned residential land and the entitlements to receive residential land without charge. The free allocation of residential land is a welfare guarantee for Chinese farmers. Those who have lost their farmer identity and transformed into urban citizens will 
automatically lose such welfare. Therefore, farmers who waive their originally owned residential land will, despite their identity as farmers, no longer engage in production or labor within their collective economic organizations, but will move to be employed by the non-agricultural sectors, and have stable work positions and economic incomes. This model is suitable for urban citizens that are engaging in non-agricultural industrial work, have stable incomes and stable employment, have purchased or plan to purchase urban housing for residence, and have the identity of farmers. In China's eastern regions where the agricultural economy is relatively developed and the rural-urban integration started early, as well as other regions with relatively developed rural economy, this model is more likely to be used. This model can, to the maximum extent possible, reduce the land occupation by rural housing and make it more possible to expand the area of arable land and the quote for the land used for urban construction. In the practice of intensive development of rural housing, the foregoing two models are used concurrently. In the intensive housing development in a certain region, an agricultural development company should also use these two models concurrently. Only in so doing, can farmers select the model of intensive housing development suiting their own needs freely to a certain extent so that farmers' interests can be effectively guaranteed. In summary, for intensive development or rural housing, multiple models should be created whereby to use rural residential land in exchange for urban housing and waive rural residential land + economic compensation, on the basis of scientific planning, law enforcement, farmers' roles and progressive implementation. In the practice of intensive development of rural housing oriented towards urbanization, marketization and modernization, efforts should be made to improve rural housing management, promote the intensive development drive for rural housing, and make contributions to the urbanization process with Chinese characteristics.

\section{REFERENCES}

[1] Babbie, E. (2013): The practice of social research (13th ed.). - Wadsworth Cengage Learning, Belmont.

[2] Habib, R.R., Yassin, N., Ghanawi, J., Haddad, P., Mahfoud, Z. (2011): Double jeopardy: assessing the association between internal displacement, housing quality and chronic illness in a low-income neighborhood. - Journal of Public Health 19: 171-182.

[3] Ho, D. C. W., Gao, W. (2013): Collective action in apartment building management in Hong Kong. - Habitat International 38: 10-17.

[4] Lai, J. (2011): Comparative evaluation of facility management services for housing estates. - Habitat International 35(2): 391-397.

[5] Najafi, A. (2010): Developing knowledge management in strategic framework of Mabena model. - World Applied Sciences Journal 9(8): 879-888.

[6] National Bureau of Statistics (2015). National Economic and Social Development. Statistics Bulletin of the People's Republic of China 2015, Beijing.

[7] Nguyen, B. L. (2012): Solutions to housing problems for low-income people in Ho Chi Minh City between re-integration and fragmentation. - Asien 103: 59-78.

[8] Nieboer, N. (2012): Private Sector Housing Management: Europe. - International Encyclopedia of Housing and Home 407-413.

[9] Opoku, R. A., Abdul-Muhmin, A. G. (2010): Housing preferences and attribute importance among low-income consumers in Saudi Arabia. - Habitat International 34: 219-227. 
[10] Peng, G. (2009): Research Bulletin on the Promotion of Sustainable Socioeconomic Development by Stimulating the Consolidation of Rural Residential Land to Encourage Saving and Intensive Use of Land. - China Land Press 1: 305-306.

[11] Means, R. S. (2011): Green Building: Project Planning \& Cost Estimating. - John Wiley \& Sons, New Jersey.

[12] Zhang, X., Shen, L., Wu, Y. (2011): Green strategy for gaining competitive advantage development: a China study. - Journal of Cleaner Production 19: 157-167. 